\title{
Analysis and Positioning of Vocational Colleges' Network Entrepreneurship Based on SWOT Analysis
}

\author{
Yan Jiang ${ }^{1, ~ a ~}$, Chengyan Cheng ${ }^{2, b}$ \\ ${ }^{1}$ Nanchang Institute of Science and Technology; Nanchang, 330108, China \\ ${ }^{2}$ Nanchang Institute of Science and Technology; Nanchang, 330108, China \\ aemail:63448054@qq.com, bemail: 297527796@qq.com
}

Keywords: vocational college students; internet startups, SWOT; positioning.

\begin{abstract}
The employment problem of higher vocational education is becoming more and more serious. Network entrepreneurship has become a new platform and new way to solve the employment problem of Higher Vocational students. This paper will systematically analyze the internal and external impact of network entrepreneurship on vocational college students, help to identify the advantages of network entrepreneurship, and provide a reasonable positioning and specific solutions for vocational college students' network entrepreneurship.
\end{abstract}

\section{Introduction}

With the rapid development of Electronic Commerce in recent years, and a more sound logistic distribution system. Net venture, characterized by it's low cost, convenient service and easy management, has gradually become an important way for college students to start their own business. A report from China Association of Employment Promotion has shown that online stores in China have directly created more than 100 million jobs, among which about 6,180,000 jobs are created by college students, accounting for $60 \%$ in total.

Higher vocational education is an important part of our nation's education system, which mainly train practical talents. The improvement of their ability to start their own business and find a job for vocational college students are important training contents in higher vocational education. In addition, vocational college students face a bigger social environment and more pressure to survive than college students, so they are more eager to survive and to start a business. They have a more sincere attitude to start their own business ${ }^{[1]}$. It's a new approach to solve the problem of employment of vocational college students taking advantage of internet to start their own business on the condition that there is a more intense competition and less job opportunities.

\section{Analysis on the status of net venture of vocational college students}

A blue paper on Chinese college students' employment report in 2015 by MyCOS Research Institute shows that the total number of college graduates is 7,490,000 in 2014. The employment rate of vocational college students has increased to $91.5 \%$ while only $2.9 \%$ college students start their own business. The ratio of vocational college students starting their own business is still higher than that of college students, up to 3.8\%, 0.5\% higher than the year of 2013. An investigation on the employment of college students shows that $6.3 \%$ of those surveyed college students choose to start their own business. While the percentage is 3.2\% at the year of 2014. In the context of a more competitive job market, the ratio of vocational college students starting their own business has increased rapidly. Choosing internet startups is a way to solve employment problem for vocational college students dreaming of starting their own business.

Presently, internet startups by vocational college students has attracted wide attention. Every vocational college will give some entrepreneurial activities to provide vocational college students with some opportunities to start their own business to enhance their abilities. From their own conditions of vocational college students, they will possess the ability and quality to start their own business. They are at the prime of their youth which is their biggest advantage of entrepreneurship. 
In addition, vocational college students are not that much burdened by their family, society and their thoughts. They can concentrate on their starting their own business. Thirdly, after several years of higher education, they have accumulated lots of knowledge. They are more likely to succeed when they are engaged in some entrepreneurship.

On the whole, vocational college education aims to cultivate applied talents and highlight their hands-on ability, so internet should become a platform for vocational students to start their own business.

\section{SWOT analysis}

\subsection{Strengths}

\subsubsection{Great market potential}

China Internet Network Information Centerpublishing Handbook on Internet Protocol (IP)-Based Networks in July 2015 shows that ${ }^{[3]}$ the number of Chinese Internet users has reached 688, 000, 000, Internet penetration $48.8 \%$. The data shows that the high cost-effective of internet platform attracts lots of online buyers, which facilitate the rapid extension of online trading. In addition, the population of people buying things through mobile phone has increased rapidly. The percentage of the netizens who surf the internet with a phone has increased to $88.9 \%$. Mobile online shopping has become an important force on the development of online shopping.

\subsubsection{Low investment, larger profits and easy access}

With the rapid development of online industries, E-commerce has become more and more popular among people which brings lots of "sunrise industries" with low investment and high profits and is suitable to vocational college students. A large amount of media get together to select "a venture rich list of Chinese college students ",among which there are 42 people whose business are connected with IT. On the whole, our nation's online business is still at an early stage and the profits of online business will still be high in a certain stage. Online business is still a preferable access for the entrepreneurs, particularly for the vocational college students

\subsubsection{Professional advantage.}

Online business needs certain professional foundation. Entrepreneurs are capable to understand social culture. The main consumers of online shopping are urban white collar workers, fashionista, and college students, which needs entrepreneurs to catch the consumer psychology and to possess an unerring instinct for marketing and lead the consumer market. That is the important content for the higher vocational education as for the above mentioned skills. We have already known that most of the vocational college have the majors which have a close connection with online business. Vocational college students can apply their knowledge to pioneering practice. By this, study and practice can be connected, complemented, mutually promoting and establish a good interactive relationship. Online business from vocational high college students can not only take advantage of their own professional advantage but also apply their knowledge to practice.

\subsubsection{Independence, full of sense of innovation.}

College students of the after1990s are an independent and innovative generation. Their independence and tendency to break the routine are quite consistent to net spirits. Students of the 1990s growing in the network environments, are most familiar with the online business and capable to start their own business. They are a group valuing personal interests. When they devote themselves into online business, they can combine their own interests with online expertise. In addition, they are full of imagination and can accept innovation.

\subsection{Weakness}

\subsubsection{Lack of investment, single mode.}

Most of the vocational college students will face the problem of lack of funds, which is always 
an important reason limiting the vocational college students to start their own business. They have no substantial assets and their possibility to secure loans or financing seems slim. In addition, the business model of vocational high college students is easily copied. Most of the college students retail their products through third party network platform like Taobao.com. This approach is characterized by its low startup cost, convenience, flexibility and low risk, but lacks innovation or characteristic, easy copy, which will lead to the deterioration of market.

\subsubsection{Lack of recognition on online business.}

One challenge that vocational high college students face is their lack of knowledge on business. In recent years, several colleges have given lectures on how to start their own business and hold several entrepreneur competitions, but basically, students' recognition on how to start their own business come from books. They lack practical experience on how to run the business. Similarly, if entrepreneurs cannot have a proper understanding or position themselves, it seems pretty unlikely for them to make a hit.

\subsection{Opportunities.}

\subsubsection{A promising market.}

In recent years, our nation's E-commerce develops rapidly. The transaction size has increased by $47.4 \%$ to 2.8 trillion in the second quarter of 2014. In addition, the emergence of portable mobile terminal such as smartphone and tablet computer will drastically change today's internet and become an important destination for the development of internet which will enlarge our nation's online market volume, diversify our nations shopping channels, provide more entrepreneurship chance for the online businessman.

\subsubsection{Policy support.}

With the emergence of the problem in employment, central and some local government and some local colleges have issued a series of beneficial policies to help and instruct vocational high college students to start their own business. These encouragement policies includes interest-free loan, entrepreneurship training, entrepreneurship course, free use places and facilities. The implementation of these policies can help solve the problems that vocational high college students face in their early stage of entrepreneurship.

\subsection{Threats}

\subsubsection{Fierce competition.}

Online business is characterized by its low market access threshold, convenience and flexibility; which attracts a lot mature and experienced entrepreneurs to take part in, which makes vocational college students face a more fierce competition. Inexperienced vocational college students have a long way to go when they tackle with problems such as how to establish characteristic, face challenge or cope with setback and so on.

\subsubsection{Other aspects.}

Vocational college students' entrepreneurship may be confused by a lot of uncertain elements due to their inexperience and young age, such as whether they can get the support from their parents, or acquire the recognition from society. Parts of the entrepreneur will choose to withdraw after a certain period of low profits. Some other college students choose to dropout school when get some profits from the market. These two extreme should also avoided.

\subsubsection{The Positioning of Network Business Startups}

When vocational students are first engaged in the Network Business startups, they must clarify their goals and make the positioning accurately. This is the key to success. Specifically speaking, business startups positioning here includes four facets such as goal positioning, mode positioning, entry point positioning, and market positioning 


\subsubsection{Goal positioning.}

Vocational students must have specific goals to start up their network business. It's very necessary to set up a goal but it shouldn't be such a lofty, unrealistic one as can make you lost. Vocational students should regard network business startups as an important way of accumulating social experiences, a transitional stage to be better prepared and adapted to the society.

\section{Mode positioning.}

Generally speaking, there are three modes for vocational students to choose if they want to start up the network business. They are online store, EC online money-making, and self-built website. Each has its advantages and disadvantages. ${ }^{[7]}$

\subsection{Online store mode.}

Opening online store through the third-party network platform is the most common way for vocational students to start up business. This mode can be divided into three types such as online retail, online small wholesale and network affiliate. The use of third-party network platform (i.e.taobao.com, paipai.com) can enhance the product's credibility and promote the increase of online customers. Therefore, it's a good idea to choose a credible third-party network platform for the beginners.

\subsection{EC online money-making mode.}

You can make money online from the internet through the use of electronic devices. This mode is simple including advertising agency, research report, software downloading etc. This requires only a small investment. Only a computer or mobile phone will do. Therefore, this mode has a great appeal for the part-time business startups, esp. vocational students. Besides, this mode can help learn more experience about how to start a business in the future.

\subsection{Self-built website mode.}

You need to build an exclusive shopping website, which consists of registering a domain name, purchasing virtual space, website design and promotion. Compared with the former two, this mode suits an experienced network business startup that has the specialties.

\section{Entry point positioning.}

Generally speaking, when inexperienced vocational students start up their business, they are lost in such issues as product's positioning and investment. This needs to make the accurate positioning when you enter this business. Choosing a right practicing program to start up business can decide not only the turn-out effects of vocational students' entrepreneurship education but the success of these business startup activities. Entry point should be chosen after full investigation. Besides, vocational students should take their majors into consideration and make the risk of this program controllable. ${ }^{[8]}$

\section{Market positioning.}

A successful market investigation can ensure the smooth carry-out of program. Only a sufficient knowledge and mastery of program-related information can better generate more effective strategies and solve the problems at ease. Most vocational students are inexperienced, having a limited knowledge of the surrounding and insufficient information. Therefore, before carrying out the program of business startups, they should not act on impulse in a blinded way. What they should do is make a full investigation of the market, using data to illustrate and making a decision reasonably.

Although the network business startup rush for vocational students is coming, they should also realize many challenges during this period such as capital-raising problem, lack of social resources, a weak awareness in the practical-ability training and team spirit. Apart from that, they should 
balance their study and career. All these problem-solving and balancing abilities need to be accumulated.

\section{The trend of internet startup}

In the foreseeable period, the network business startup rush for vocational students will endure for a long time and it will present the following characteristics.

Firstly, the scale continues to be enlarged. The employment problem for vocational students will become increasingly prominent. More and more graduates choose to start up network business, which is likely to become a trend. At present, the self-employment ratio for vocational students ranks first among the college students. And this trend will persist. Our higher education focuses more on generating self-employed businessmen, which will bring more vocational students in the flow of network business startups.

Secondly, the trend includes a diversified development. With the development of network economy, more and more entrepreneurs will throw themselves in this business, which will make its subjects more diversified. This means the mode of network businesses startup will encounter a fiercer competition and it will be forced to become more diversified.

Thirdly, the trend includes the rise of entrepreneurship education. Network business startup is a new path to solve the employment problem. It is bound to be attached importance to by the country, society, and every college. The education of network business startup will definitely be taken into the training system as an important criterion to measure students' comprehensive quality. Hence, more business startups will be supported and encouraged, and more relevant service and training will be developed.

In a word, with the rapid development of current network economy, a combination of social environment and self-edges in pursuing network business startup will show a new way for vocational students. In the Internet Era, vocational students, as the young and creative social group, should seize this opportunity, make full use of their own advantages, find the accurate positioning, grasp the entrepreneurship trend, and try their best to become top in the network business startups.

\section{References}

[1] HuiGuilan, College students respond to a number of internet entrepreneurship rational thinking [J] Techno economics \& Management Research, 2010(5):105.

[2] Ding Wen yun, Jia Shao hua. Vocational students internet entrepreneurship analysis [J].Vocational Education Research, 2007(7):66.

[3] [RB/OL].http://www.cnnic.net.cn/hlwfzyj/hlwxzbg/hlwtjbg/201507/t20150722_52624.htm.

[4] Zhu Song jie. Advantage and problem analysis on undergraduates internet entrepreneurship [J], Technology and Market, 2012(10):188.

[5] Li ling ji. Internet entrepreneurship, are college students ready for it? [N], China Education Daily, 2009-8-19(5).

[6] Huang Wei .A Feasibility Study on College Students' Online Entrepreneurial Approaches in the Mobile Times [J].Journal of higher Education Management, 2014(3):118.

[7] Cheng Ling yun. The analysis on the internet entrepreneurship mode of vocational college students. [J].Education and vocation, 2012(29):94.

[8] Chen Xuezhong. Entry point option of entrepreneurship practice on undergraduates [J]. Career Horizon, 2015(5):85-86. 